\title{
Effectiveness of $2 \%$ peracetic acid for the disinfection of gutta-percha cones
}

\section{Ana Carolina Rodrigues Danzi Salvia(a) \\ Guilherme Rodrigues Teodoro(a) Ivan Balducci(b) \\ Cristiane Yumi Koga-Ito ${ }^{(a)}$ \\ Simone Helena Gonçalves de Oliveira $^{(a)}$}

\footnotetext{
(a) Department of Biosciences and Oral Diagnosis, São José dos Campos Dental School, Univ. Estadual Paulista (UNESP), São José dos Campos, SP, Brazil.

(b) Department of Social Dentistry and Pediatric Dentistry, São José dos Campos Dental School, Univ. Estadual Paulista (UNESP), São José dos Campos, SP, Brazil.
}

\begin{abstract}
The aim of this study was to evaluate the effectiveness of $2 \%$ peracetic acid for the disinfection of gutta-percha cones contaminated in vitro with Escherichia coli, Staphylococcus aureus, Streptococcus mutans, Candida albicans and Bacillus subtilus (in spore form). Two hundred and twenty-five gutta-percha cones were contaminated with standardized suspensions of each microorganism and incubated at $37^{\circ} \mathrm{C}$ for $24 \mathrm{~h}$. The cones were divided into 10 experimental groups $(\mathrm{n}=15)$, according to the microorganism tested and disinfection testing times. The disinfection procedure consisted of immersing each cone in a plastic tube containing the substance. The specimens remained in contact with the substance for 1 or 2.5 minutes. Afterwards, each cone was transferred to a $10 \%$ sodium thiosulphate solution $\left(\mathrm{Na}_{2} \mathrm{~S}_{2} \mathrm{O}_{3}\right)$ to neutralize the disinfectant. Microbial biofilms adhering to the cones were dispersed by agitation. Aliquots of $0.1 \mathrm{ml}$ of the suspensions obtained were plated on Sabouraud dextrose agar, or brain and heart infusion agar, and incubated at $37^{\circ} \mathrm{C}$ for $24 \mathrm{~h}$. The results were expressed in colony forming units $(\mathrm{CFU} / \mathrm{ml})$ and the data were submitted to the Wilcoxon Signed Rank Test (level of significance at 0.05). A significant reduction was observed, after 1 minute of exposure, in the test solution for C. albicans ( $\mathrm{p}=0.0190), S$. aureus $(\mathrm{p}=0.0001), S$. mutans $(\mathrm{p}=0.0001), B$. subtilis $(\mathrm{p}=0.0001)$, and E. coli $(\mathrm{p}=0.0001)$. After 2.5 minutes of exposure, $100 \%$ of the microbial inocula were eliminated. It was concluded that the $2 \%$ peracetic acid solution was effective against the biofilms of the tested microorganisms on gutta-percha cones at 1 minute of exposure.
\end{abstract}

Descriptors: Disinfection; Endodontics; Microbiology.

\section{Introduction}

Microorganisms play a fundamental role in the etiology of pulpar and periapical diseases, and their elimination from the root canal by chemical and mechanical procedures is one of the essential steps to secure successful treatment. ${ }^{1,2,3,4,5,6}$ In clinical practice, the dentist is occasionally faced with the problem of re-infection after endodontic treatment. Moreover, penetration of bacteria into the blood stream of systemically compromised patients should be prevented because of the risk of infective endocarditis. ${ }^{1}$ One possible explanation for this phenomenon may be the introduction of contaminated gutta-percha cones into the root canal. ${ }^{2}$ Therefore, much care must be taken during this procedure to prevent contamination of filling materials. ${ }^{3,7}$ 
Gutta-percha cones are the most commonly used material for filling the root canal. They are biocompatible, dimensionally stable, radiopaque, thermoplastic and easily removed from the root canal. Even though gutta-percha cones are produced under aseptic conditions and have potentially antimicrobial properties, especially owing to their zinc oxide component, they can be contaminated by handling and also by aerosols and physical sources during the storage process. ${ }^{2,3,8,9}$ Therefore, the handling of gutta-percha cones must follow the basic principles of infection control. In addition, gutta-percha cones that have been in contact with patients should be discarded. ${ }^{1}$ Owing to the thermoplastic characteristic of gutta-percha cones, they may not be sterilized by the conventional process in which moist or dry heat is used, because this may cause alteration to the gutta-percha structure. ${ }^{2,3,4,6,8,10}$ For this reason, previous studies suggested that several different chemical agents could be used for the rapid decontamination of gutta-percha cones in dentistry.

Peracetic acid has been cited in the literature as a promising alternative for disinfection due to its antimicrobial efficiency. However, the use of peracetic acid has not been reported in the literature as a gutta-percha cone disinfectant. Therefore, the purpose of this study was to evaluate in vitro the effectiveness of peracetic acid for the rapid decontamination of gutta-percha cones.

\section{Material and Methods}

The following microorganisms were used for this study: Escherichia coli (ATCC 23922), Staphylococcus aureus (ATCC 6538), Streptococcus mutans (ATCC 35688), Candida albicans (ATCC 18804) and Bacillus subtilus (ATCC 19659) (spore form).

Two hundred and twenty-five \#70 Tanari R8 gutta-percha cones (Tanariman Industrial, Manacapurú, AM, Brazil) were sterilized by cobalt- 60 gamma radiation (25 kGy/6 h; Embrarad, Cotia, SP, Brazil).

Isolated 24-h colonies of pure cultures of each microorganism were grown on brain heart infusion agar plates (Difco, Detroit, MI, USA) or, in the case of C. albicans, Sabouraud dextrose agar plates (Difco, Detroit, MI, USA). The plates were incubat- ed aerobically at $37^{\circ} \mathrm{C}$, and in an atmosphere of $5 \%$ $\mathrm{CO}_{2}$ for $S$. mutans, for 24 hours.

The cones were divided into 10 experimental groups $(\mathrm{n}=15)$ and 5 control groups $(\mathrm{n}=15)$. Then, the cones were contaminated by immersion in tubes containing $10 \mathrm{ml}$ of brain heart infusion broth or Sabouraud dextrose broth (for C. albicans) inoculated with $0.1 \mathrm{ml}$ of standardized suspensions containing $1 \times 10^{6}$ cells $/ \mathrm{ml}$ of each microorganism obtained by spectrophotometry (Shinadzu model UV-1203, Kyoto, Japan) in sterile saline solution $(0.9 \% \mathrm{NaCl})$. The parameters adopted for each microorganism were previously standardized: Candida albicans, $530 \mathrm{~nm}, \mathrm{OD}=0.284 ; S$. mutans, $398 \mathrm{~nm}$, $\mathrm{OD}=0.620 ;$ S. aureus, $490 \mathrm{~nm}, \mathrm{OD}=0.374 ;$ E. coli, $590 \mathrm{~nm}, \mathrm{OD}=0.324 ;$ B. subtilis spores, $307 \mathrm{~nm}$, $\mathrm{OD}=0.178$. The methodology used to obtain the $B$. subtilis spore suspension was that described by $\mathrm{Ku}-$ roiwa et al. ${ }^{11}$ The cones were incubated at $37^{\circ} \mathrm{C}$ for $24 \mathrm{~h}$ (and 5\% $\mathrm{CO}_{2}$ for $S$. mutans) for the purpose of promoting surface contamination. Afterwards, they were briefly dried in a sterile paper filter and then disinfected.

The disinfection procedure consisted of immersing each gutta-percha cone in a plastic tube (Eppendorf) containing the $2 \%$ peracetic acid solution (Sekusept aktiv - Fórmula \& Ação, São Paulo, SP, Brazil), making sure to cover the cone's entire surface. The solution was prepared according to the manufacturer's instructions. The specimens remained in contact with the substance for 1 or 2.5 minutes. Afterwards, each cone was transferred to a tube containing a $10 \%$ sodium thiosulphate solution $\left(\mathrm{Na}_{2} \mathrm{~S}_{2} \mathrm{O}_{3}\right)$, and remained there for 4 minutes to neutralize the activity of the peracetic acid solution. The cones of the control group $(\mathrm{n}=15)$ were immersed in sterile distilled water for 1 or 2.5 minutes, following the same procedures described above.

All the cones (including those of the control group) were then immersed in tubes containing sterile physiologic solution $(0.9 \% \mathrm{NaCl})$, and vortexed for 30 seconds to detach any remaining microbial cells. Next, $10^{-1}$ and $10^{-2}$ dilutions were obtained in $0.85 \% \mathrm{NaCl}$, and $0.1-\mathrm{ml}$ aliquots of all suspensions obtained were double-plated on Sabouraud dextrose agar or brain heart infusion agar and incubated at 
$37^{\circ} \mathrm{C}$ (and $5 \% \mathrm{CO}_{2}$ for $S$. mutans) for $24 \mathrm{~h}$.

The results were expressed in colony forming units per milliliter $(\mathrm{CFU} / \mathrm{ml})$, and the data were compared by the Wilcoxon Signed Rank test (level of significance set at 0.05 ).

\section{Results}

The values of percentage reduction in microorganism counts after exposure to peracetic acid are shown in Table 1. A significant reduction in microbial counts was observed after 1 minute of exposure to the peracetic acid solution for all the microorganisms tested. All microorganisms were completely eliminated after 2.5 minutes of exposure.

\section{Discussion}

Peracetic acid-based disinfectants have been used in the food industry and by water or sewage treatment companies, and also for the decontamination and sterilization of thermosensitive medical and hospital equipment and devices. This substance works quickly and is effective against bacteria, fungi, viruses and spores. ${ }^{12,13}$ Unlike most chemical disinfectants, it is not inactivated in the presence of organic material, ${ }^{12,14}$ does not leave residues and does not produce byproducts harmful to the environment, because its mechanism of action involves the release of free oxygen and hydroxyl radicals decomposing in oxygen, water and acetic acid. ${ }^{12,13,14,15}$ It can be utilized over a broad temperature spectrum (0 to $40^{\circ} \mathrm{C}$ ), with hard water, and is effective in the 3.0 to $7.5 \mathrm{pH}$ range. ${ }^{14}$ These features of peracetic acid raised the hypothesis that it could be a valid alternative for the disinfection of gutta-percha cones.

Table 1 - Percentage reduction in microbial counts for $C$. albicans, S. aureus, S. mutans, B. subtilis, and E. coli after 1 minute of exposure to peracetic acid.

\begin{tabular}{c|c|c|c|c|c}
\hline Microorganism & $\mathrm{n}$ & Q1 & median & Q3 & $\mathrm{p}$-value* \\
\hline C. albicans & 15 & 94.91 & 100.00 & 100.00 & 0.0190 \\
\hline S. aureus & 15 & 100.00 & 100.00 & 100.00 & 0.0001 \\
\hline S. mutans & 15 & 100.00 & 100.00 & 100.00 & 0.0001 \\
\hline B. subtilis & 15 & 100.00 & 100.00 & 100.00 & 0.0001 \\
\hline E. coli & 15 & 100.00 & 100.00 & 100.00 & 0.0001 \\
\hline
\end{tabular}

*Wilcoxon Signed Rank test ( $p \leq 0.05)$.
The $S$. aureus, S. mutans, E. coli and C. albicans species were selected for this study with the aim of including Gram-positive and Gram-negative bacterial species, and a fungal species as well. Moreover, sporulated bacilli were also included owing to this form's high resistance to disinfection methods.

Several substances have already been tested for gutta-percha cone disinfection; however, the high toxicity of some substances and the deleterious effects of others call for alternative methods. In fact, both aqueous and detergent solutions of $2 \%$ chlorhexidine were reported to be effective in decontaminating gutta-percha cones contaminated by Staphylococcus aureus, Enterococcus faecalis, Escherichia coli, Candida albicans and spores of Bacillus subtilis after 5 minutes of exposure. ${ }^{3}$ Cardoso et al. ${ }^{10}$ also reported that gutta-percha cone decontamination may be achieved with $2 \%$ chlorhexidine after 1 minute. On the other hand, Gomes et al. ${ }^{8}$ showed that $0.2 \%, 1 \%$, and $2 \%$ chlorhexidine, in either liquid or gel form, were not effective for the high disinfection requirements of gutta-percha cones contaminated with spores of $B$. subtilis, even after 72 hours of contact.

Sodium hypochlorite solutions at concentrations of $1 \%, 2.5 \%$ and $5.25 \%$ have also proven effective in disinfecting gutta-percha cones. ${ }^{10,16}$ Nevertheless, Isci et al. ${ }^{9}$ showed that a $5.25 \% \mathrm{NaOCl}$ solution caused physical alterations on resilon cones after 5 minutes. Moreover, Valois et al. ${ }^{6}$ observed aggressive deteriorative effects on gutta-percha cone elasticity for $5.25 \% \mathrm{NaOCl}$ at 1 minute.

Some studies reported that a $2 \%$ glutaraldehyde solution was unable to decontaminate gutta-percha cones inoculated with $B$. subtilis, even after $15 \mathrm{~min}$ utes of contact. ${ }^{2,17}$ On the other hand, another study showed that the same concentration was bactericidal at 1 minute and sporicidal after 15 minutes of exposure. ${ }^{10}$ Despite its benefits, glutaraldehyde releases toxic vapors which can cause eye, nose and throat irritation, allergy, contact dermatitis, asthma and rhinitis. In addition, it should be used in well-ventilated places and requires the use of masks, gloves and eyeglasses. Because of glutaraldehyde toxicity, items immersed in this solution, especially those made with porous materials, must be washed thor- 
oughly in running water to avoid the release of toxic product residues. ${ }^{12}$

Previous studies reported that immersion in a $10 \%$ polyvinylpyrrolidone-iodine aqueous solution (10\% PVP-I alone or combined with $96^{\circ}$ GL alcohol) was effective for gutta-percha cone disinfection. ${ }^{4,10}$ Cardoso et al. ${ }^{18}$ also reported that $0.3,1$, 2 and 3\% iodine alcohol destroyed all the bacterial cells (S. aureus, E. faecalis, E. coli) after 1 minute, without sporicidal activity after 15 minutes. Nevertheless, alcohol tends to dry gutta-percha cones. ${ }^{18}$

The present study showed that the use of a $2 \%$ peracetic acid solution resulted in a significant reduction in the growth of microorganisms tested after 1 minute of exposure, with low counts of remaining C. albicans. The persistence of this yeast may be explained by its complex, eukaryotic organization. Previous studies reported the effectiveness of peracetic acid for the disinfection of other materials. Similarly to other disinfectants, peracetic acid solution has been found to be more effective against microorganisms in suspension than against bacterial biofilms on stainless steel and glass surfaces. ${ }^{14} \mathrm{~A}$ $0.2 \%$ peracetic acid-based disinfectant promoted a high level of disinfection of heat-polymerized, chemically-activated and microwave-polymerized acrylic

\section{References}

1. Dumani A, Yoldas O, Isci AS, Köksal F, Kayar B, Polat E. Disinfection of artificially contaminated resilon cones with chlorhexidine and sodium hypochlorite at different time exposures. Oral Surg Oral Med Oral Pathol Oral Radiol Endod. 2007 Mar;103(3):82-5.

2. Özalp N, Ökte Z, Özcelik B. The rapid sterilization of guttapercha cones with sodium hypochlorite and glutaraldehyde. J Endod. 2006 Dec;32(12):1202-4.

3. Redmerski R, Bulla JR, Moreno T, Garcia LB, Cardoso CL. Disinfection of gutta-percha cones with chlorhexidine. Braz J Microbiol. 2007 Oct-Dec; 38(4):649-55.

4. Souza RE, Souza EA, Sousa-Neto MD, Pietro RCLR. In vitro evaluation of different chemical agents for the decontamination of gutta-percha cones. Pesqui Odontol Bras. 2003 JanMar;17(1):75-7.

5. Tanomaru JMGT, Pappen FG, Tanomaru Filho M, Spolidorio DMP, Ito IY. In vitro antimicrobial activity of different guttapercha points and calcium hydroxide pastes. Braz Oral Res. 2007 Jan-Mar;21(1):35-9. resins contaminated with either human saliva or $\mathrm{Ba}$ cillus subtilis after 5 minutes. ${ }^{12}$ A $60-\mathrm{mg} / \mathrm{l}$ peracetic acid solution at $25^{\circ} \mathrm{C}$ promoted an $8.0 \mathrm{log}$-cycle reduction of E. coli and $S$. aureus on a stainless steel device in 3.1 minutes of contact. ${ }^{12}$ On the other hand, Marques et al. ${ }^{19}$ stated that a $0.3 \%$ peracetic acid solution was unable to completely eliminate $S$. aureus cells clinging to stainless steel and glass surfaces.

Despite the good performance of peracetic acid for the disinfection of gutta-percha cones, Bounoure et al. ${ }^{20}$ reported that repeated exposure to peracetic acid is toxic. Animals chronically exposed to this substance have shown weight loss, an increase in mortality, and skin, mucous membrane, and respiratory irritations. Currently, no standards regulate the amount of peracetic acid to which someone can be exposed. Therefore, more studies on the toxicity of this material are required to allow its safe use.

\section{Conclusion}

Based on the results obtained in this study, it can be concluded that the $2 \%$ peracetic acid solution was effective against the tested microorganisms after 1 minute of exposure, and may be a valid alternative for the disinfection of gutta-percha cones.

6. Valois CRA, Silva LP, Azevedo RB. Structural Effects of sodium hypochlorite solutions on gutta-percha cones: atomic force microscopy study. J Endod. 2005 Oct;31(10):749-51.

7. Maniglia-Ferreira C, Silva Jr JBA, Monteiro de Paula RC, Feitosa JPA, Cortez DGN, Zaia AA et al. Brazilian guttapercha points. Part I: chemical composition and X-ray diffraction analysis. Braz Oral Res. 2005 Jul-Sep;19(3):193-7.

8. Gomes BPFA, Vianna ME, Matsumoto CU, Silva Rossi VP, Zaia AA, Ferraz CCR, et al. Disinfection of gutta-percha cones with chlorhexidine and sodium hypochlorite. Oral Surg Oral Med Oral Pathol Oral Radiol Endod. 2005 Oct;100(4):512-7.

9. Isci S, Yoldas O, Dumani A. Effects of sodium hypochlorite and chlorhexidine solutions on resilon (synthetic polymer based root canal filling material) cones: an atomic force microscopy study. J Endod. 2006 Oct;32(10):967-9.

10. Cardoso CL, Redmerski R, Bittencourt NLR, Kotaka CR. Effectiveness of different chemical agents in rapid decontamination of gutta-percha cones. Braz J Microbiol. 2000 JanMar;31(1):67-71. 
11. Kuroiwa K, Nakayama H, Kuwahara K, Tamagawa K, Hattori $\mathrm{K}$, Murakami K, et al. Augmenting effect of acetic acid for acidification on bactericidal activity of hypochlorite solution. Lett Appl Microbiol. 2003 Dec; 36(1):46-9.

12. Chassot ALC, Poisl MI, Samuel SMW. In vivo and in vitro evaluation of the efficacy of a peracetic acid-based disinfectant for decontamination of acrylic resins. Braz Dent J. 2006;17(2):117-21.

13. Loukili NH, Granbastien B, Faure K, Guery B, Beaucaire G. Effect of different stabilized preparations of peracetic acid on biofilm. J Hosp Infect. 2006 May;63(1):70-2.

14. Kunigk L, Almeida MCB. Action of peracetic acid on Escherichia coli and Staphylococcus aureus in suspension or settled on stainless steel surfaces. Braz J Microbiol. 2001 JanMar;32(1):38-41.

15. Naenni N, Thoma K, Zehnder M. Soft tissue dissolution capacity of currently used and potential endodontic irrigants. J Endod. 2004 Nov;30(11):785-7.
16. Cardoso CL, Kotaka CR, Redmerski R, Guilhermetti M, Queiroz AF. Rapid decontamination of gutta-percha cones with sodium hypochlorite. J Endod. 1999 Jul;25(7):498-501.

17. Cardoso CL, Kotaka CR, Guilhermetti M, Hidalgo MM. Rapid sterilization of gutta-percha cones with glutaraldehyde. J Endod. 1998 Aug;24(8):561-3.

18. Cardoso CL, Redmerski R, Garcia LB, Hidalgo MM. Descontaminação rápida de cones de guta-percha com álcool iodado. Acta Scientiarium. 2001;23(3):719-24.

19. Marques SC, Rezende JGOS, Alves LAF, Silva BC, Alves E, Abreu LR, et al. Formation of biofilms by Staphylococcus aureus on stainless steel and glass surfaces and resistance to some selected chemical sanitizers. Braz J Microbiol. 2007 JulSep;38(3):538-543.

20. Bounoure F, Fiquet H, Arnaud P. Comparison of hydrogen peroxide and peracetic acid as isolator sterilization agents in a hospital pharmacy. Am J Health Syst Pharm. 2006 Mar; 63(5):451-5. 